\title{
Identification and Preclinical Evaluation of a Radiofluorinated Benzazepine Derivative for Imaging the GluN2B Subunit of the Ionotropic NMDA Receptor
}

\author{
Ahmed Haider*1, Irina Iten*1, Hazem Ahmed ${ }^{1}$, Adrienne Müller Herde ${ }^{1}$, Stefan Gruber ${ }^{1}$, Stefanie D. Krämer ${ }^{1}$, \\ Claudia Keller ${ }^{1}$, Roger Schibli ${ }^{1,2}$, Bernhard Wünsch ${ }^{3}$, Linjing Mu ${ }^{1,2}$, and Simon M. Ametamey ${ }^{1}$ \\ ${ }^{1}$ Institute of Pharmaceutical Sciences, ETH Zurich, Zurich, Switzerland; ${ }^{2}$ Department of Nuclear Medicine, University Hospital \\ Zurich, Zurich, Switzerland; and ${ }^{3}$ Institute of Pharmaceutical and Medicinal Chemistry, University of Münster, Münster, Germany
}

The previously reported ${ }^{11} \mathrm{C}$-labeled GluN2B PET radioligand ${ }^{11} \mathrm{C}$ Me-NB1 served as a starting point for derivatization and led to the successful development of a radiofluorinated analog designated $(R)-{ }^{18} \mathrm{~F}-\mathrm{OF}-\mathrm{Me}-\mathrm{NB} 1$. Given the short physical half-life of $20.3 \mathrm{~min}$ for ${ }^{11} \mathrm{C},(R)-{ }^{18} \mathrm{~F}-\mathrm{OF}-\mathrm{Me}-\mathrm{NB} 1$ with a physical half-life of $109.8 \mathrm{~min}$ would allow satellite distribution to nuclear medicine facilities without an on-site cyclotron. Methods: Two fluorinated Me-NB1 derivatives, OF-Me-NB1 and PF-Me-NB1, were synthesized. On chiral resolution, the respective enantiomers were radiolabeled with ${ }^{11} \mathrm{C}$ and assessed in a proof-of-concept study by applying in vitro autoradiography on rodent brain sections. On the basis of the autoradiograms, $(R)$-OF-Me-NB1 was selected for radiofluorination and preclinical evaluation by ex vivo autoradiography, PET imaging, biodistribution, and metabolite studies on Wistar rats. To rule out off-target binding to the $\sigma_{1}$ receptor $\left(\sigma_{1} R\right)$, brain uptake of $(R)-{ }^{18} \mathrm{~F}-\mathrm{OF}$ Me-NB1 in wild-type mice was compared with that in $\sigma_{1} R$ knock-out mice. Results: Autoradiographic assessment revealed that both enantiomers of ${ }^{11} \mathrm{C}-\mathrm{PF}-\mathrm{Me}-\mathrm{NB} 1$ distributed homogeneously across all brain regions on rodent brain sections. In contrast, the 2 enantiomers of ${ }^{11} \mathrm{C}$-OF-Me-NB1 exhibited an entirely different behavior. Although $(S)-{ }^{11} \mathrm{C}-\mathrm{OF}-\mathrm{Me}-\mathrm{NB} 1$ bound to virtually all brain regions, with considerable $\sigma_{1} R$ binding, $(R)-{ }^{11} \mathrm{C}-\mathrm{OF}-\mathrm{Me}-\mathrm{NB} 1$ exhibited high selectivity and specificity for the GluN2B-rich rat forebrain. These findings were confirmed for the radiofluorinated analog $(R)^{-18} \mathrm{~F}-\mathrm{OF}-$ Me-NB1, which was obtained via copper-mediated radiofluorination in radiochemical yields of $13 \%-25 \%$ and molar activities ranging from 61 to $168 \mathrm{GBq} / \mu \mathrm{mol}$. PET imaging and biodistribution studies on Wistar rats indicated an appropriate pharmacokinetic profile and high in vivo specific binding of $(R)-{ }^{18} \mathrm{~F}-\mathrm{OF}-\mathrm{Me}-\mathrm{NB} 1$ as revealed by blocking studies with the GluN2B antagonist CP101,606. Off-target binding to the $\sigma_{1} R$ was excluded by PET imaging of $\sigma_{1} R$ knock-out mice. Half-maximal receptor occupancy by CP101,606 occurred at $8.3 \mu \mathrm{mol} / \mathrm{kg}$ (intravenous). Conclusion: $(R)-{ }^{18} \mathrm{~F}-\mathrm{OF}-\mathrm{Me}-\mathrm{NB} 1$ is a promising radiofluorinated probe that exhibits specificity and selectivity for the GluN2B-containing $N$-methyl-D-aspartate complex and enables in vivo target occupancy studies on rodents.

Received Mar. 28, 2018; revision accepted Jul. 4, 2018.

For correspondence or reprints contact: Simon M. Ametamey, Radiopharmaceutical Sciences, Institute of Pharmaceutical Sciences, ETH Zurich, VladimirPrelog Weg 4, CH-8093 Zurich, Switzerland.

E-mail: simon.ametamey@pharma.ethz.ch

${ }^{\star}$ Contributed equally to this work.

Published online Jul. 20, 2018.

COPYRIGHT (C 2019 by the Society of Nuclear Medicine and Molecular Imaging.
Key Words: NMDA; GluN2B; PET; receptor occupancy; CP101,606

J Nucl Med 2019; 60:259-266

DOI: 10.2967/jnumed.118.212134

$\mathbf{E}$

xcessive glutamatergic stimulation leads to the activation of proapoptotic neuronal signaling pathways contributing to neurodegeneration (1). This excitotoxicity state is associated with numerous pathologic conditions of the central nervous system, including Parkinson disease, Alzheimer disease, neuropathic pain, and depression, as well as ischemic brain injury $(2,3)$. Because of their high permeability for calcium ions, $N$-methyl-D-aspartate (NMDA) receptors are particularly implicated in glutamate-mediated neurotoxicity. Among the NMDA receptor subunits, GluN2B has emerged as a promising target for subtype-selective modulation. Accordingly, therapeutic interventions by GluN2B antagonists have proven to be effective for Parkinson disease, cerebral ischemia, neuropathic pain, and depression in preclinical trials (47). In contrast to broad-spectrum NMDA channel blockers, selective GluN2B antagonists have an improved safety profile with lower cognitive side effects, as GluN2B is hardly expressed in the cerebellum, a brain region that regulates cognitive functions through mapping of cerebral association networks $(8,9)$. Since the discovery of the N-terminal domain binding pocket of GluN2Bcarrying NMDA receptors, several antagonists have been developed, and promising candidates such as CP101,606 and CERC-301 (MK-0657) have been evaluated in clinical trials (9-11). Despite high expectations that arose from animal studies, initial euphoria has dissipated as increasing numbers of clinical trials with GluN2Bselective drug candidates have shown limited efficacy (11-13). It is therefore crucial to guide these clinical trials with diagnostic tools such as PET, which allows one to predict and assess target engagement at a given drug dose in vivo (14).

We recently reported on the development of ${ }^{11} \mathrm{C}-\mathrm{Me}-\mathrm{NB} 1$, a 3benzazepine-based GluN2B PET tracer with promising attributes that make it possible to address the several issues that limited previously reported GluN2B imaging probes (15). A major limitation of ${ }^{11} \mathrm{C}-\mathrm{Me}-\mathrm{NB} 1$ remains the short physical half-life of ${ }^{11} \mathrm{C}$ (20.3 min). Particularly, this limitation confines the use of ${ }^{11} \mathrm{C}$ Me-NB1 to facilities with an on-site cyclotron. To overcome this limitation, we envisioned the development of a suitable ${ }^{18} \mathrm{~F}$ (physical half-life, 109.8 min)-labeled analog of ${ }^{11} \mathrm{C}-\mathrm{Me}-\mathrm{NB} 1$. 


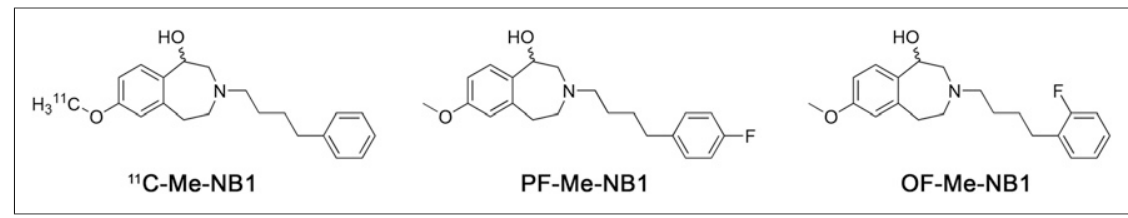

FIGURE 1. Chemical structures of ${ }^{11} \mathrm{C}-\mathrm{Me}-\mathrm{NB} 1, \mathrm{PF}-\mathrm{Me}-\mathrm{NB} 1$, and OF-Me-NB1.

radioligand for imaging GluN2B receptors and, furthermore, that it can be used to study the in vivo receptor occupancy of CP101,606, the only existing GluN2B antagonist with reported clinical efficacy $(4,16,17)$. Derivatives of 3-benzazepin-1-ol have been shown to generally exhibit high selectivity over a series of central nervous system receptors, including the phencycli-

Therefore, we synthesized 2 fluorinated analogs, PF-Me-NB1 and OF-Me-NB1 (Fig. 1), and evaluated their utility as imaging agents for the GluN2B subunit of the ionotropic NMDA receptor. Because of the distinct enantiomeric behavior observed for ${ }^{11} \mathrm{C}-\mathrm{Me}-\mathrm{NB} 1$, both fluorinated derivatives were separated into their enantiomerically pure $(R)$ and $(S)$ forms. We initially labeled the 4 enantiomers $(R)$-OFMe-NB1, $(S)$-OF-Me-NB1, $(R)$-PF-Me-NB1, and $(S)$-PF-Me-NB1 with ${ }^{11} \mathrm{C}$ and assessed in a proof-of-concept study their performance characteristics by in vitro autoradiography using rodent brain sections. On the basis of the autoradiograms, $(R)$-OF-Me-NB1 was selected for radiofluorination and preclinical evaluation. The results of the preclinical study showed that $(R)-{ }^{18} \mathrm{~F}-\mathrm{OF}-\mathrm{Me}-\mathrm{NB} 1$ is a promising dine-binding site and the $\sigma_{2}$ receptor; however, off-target binding to $\sigma_{1}$ receptor $\left(\sigma_{1} R\right)$ has been reported, wherein a slight structural modification can shift the binding profile from a GluN2B binder to a $\sigma_{1} \mathrm{R}$-selective ligand (18). Therefore, to rule out off-target binding to the $\sigma_{1} \mathrm{R}$, the in vivo brain uptake of $(R)-{ }^{18} \mathrm{~F}-\mathrm{OF}-\mathrm{Me}-\mathrm{NB} 1$ in wildtype mice was compared with $\sigma_{1} \mathrm{R}$-knock-out $\left(\sigma_{1} \mathrm{R}-\mathrm{KO}\right)$ mice.

\section{MATERIALS AND METHODS}

The syntheses of precursors and reference compounds-including ${ }^{1} \mathrm{H}$ - and ${ }^{13} \mathrm{C}$-nuclear MR; high-resolution mass spectrometry characterizations; and high-performance liquid chromatography conditions,

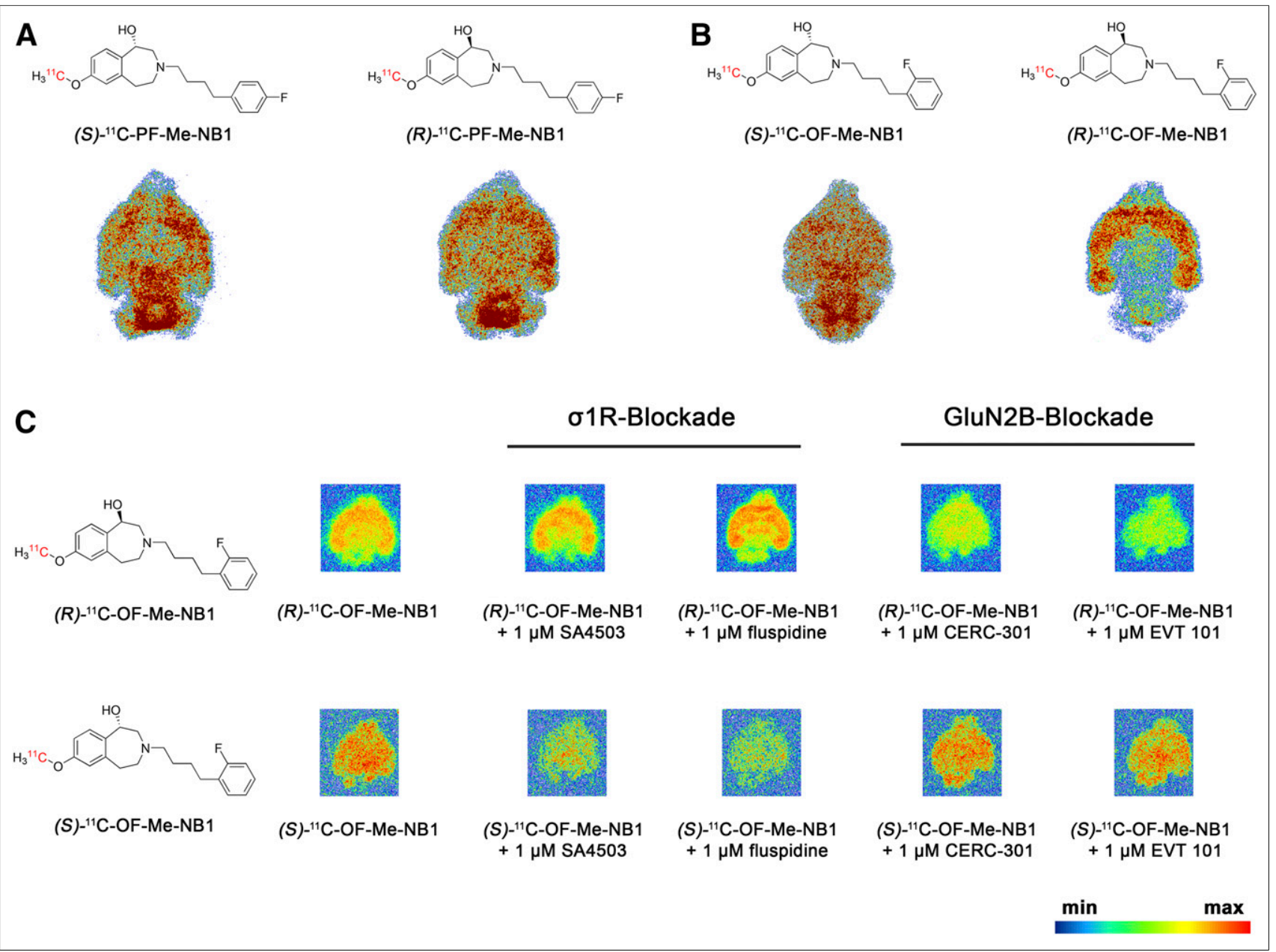

FIGURE 2. Representative in vitro autoradiograms with ${ }^{11} \mathrm{C}$-labeled probes on coronal rat and mouse brain sections. (A) Para-fluorinated derivatives $(R)$ - and $(S)-{ }^{11} \mathrm{C}-\mathrm{PF}-\mathrm{Me}-\mathrm{NB} 1$ revealed binding across all rat brain regions, with cerebellum showing highest accumulation. (B) Ortho-fluorinated derivatives $(R)$ - and $(S)-{ }^{11} \mathrm{C}-\mathrm{OF}-\mathrm{Me}-\mathrm{NB} 1$ exhibited distinct binding patterns. Although $(S)$-enantiomer distributed uniformly across all rat brain regions, $(R)$ enantiomer revealed high selectivity for GluN2B-expressing forebrain regions. (C) Distinct binding patterns of $(R)$ - and $(S)-{ }^{11} \mathrm{C}-\mathrm{OF}-\mathrm{Me}-\mathrm{NB} 1 \mathrm{were}$ further confirmed on mouse brain sections. Blocker screening revealed GluN2B specificity for $(R)$-enantiomer and considerable $\sigma_{1} R$ binding of $(S)$-enantiomer. 
chiral separations, and circular dichroism spectra-are presented as supplemental material (available at http://jnm.snmjournals.org). Animal studies were performed in compliance with the Swiss Animal Protection Law and the ARRIVE (Animal Research: Reporting of In Vivo Experiments) guidelines and after approval from the local veterinary office of the Canton Zurich, Switzerland. Wistar rats and $\mathrm{CD} 1 \mathrm{mice}$ were purchased from Charles River, and $\sigma_{1} \mathrm{R}-\mathrm{KO}$ mice were provided by Envigo. All animals were kept under standard conditions as previously reported (15).

\section{Radiochemistry}

${ }^{18} \mathrm{~F}$-fluoride ions were produced by bombardment of $98 \%$ enriched $\left({ }^{18} \mathrm{O}\right)$ water via the ${ }^{18} \mathrm{O}(\mathrm{p}, \mathrm{n}){ }^{18} \mathrm{~F}$ nuclear reaction in a Cyclone $18 / 9$ cyclotron (18-MeV; IBA) with a starting activity of approximately 50 $\mathrm{GBq}$ in $0.94 \mathrm{~mL}$ of ${ }^{18} \mathrm{O}$-enriched water. The activity was trapped on an anion-exchange cartridge (Waters SepPak Accell QMA cartridge, carbonate) and subsequently eluted with a solution of Kryptofix 222 (6.3 $\mathrm{mg} / \mathrm{mL}, 16.7 \mu \mathrm{mol} / \mathrm{mL}$; Merck), $\mathrm{K}_{2} \mathrm{C}_{2} \mathrm{O}_{4}(1.0 \mathrm{mg} / \mathrm{mL}, 5.4 \mu \mathrm{mol} / \mathrm{mL})$, and $\mathrm{K}_{2} \mathrm{CO}_{3}(0.1 \mathrm{mg} / \mathrm{mL}, 0.7 \mu \mathrm{mol} / \mathrm{mL})$ in a mixture of acetonitrile and $\mathrm{H}_{2} \mathrm{O}(4: 1,0.9 \mathrm{~mL})$, followed by azeotropic drying with acetonitrile $(3 \times 1 \mathrm{~mL})(19)$. A borosilicate glass Reacti-Vial (Wheaton Industries, $6 \mathrm{~mL}$ ) sealed with a plastic cap containing a Teflon (DuPont)-faced rubber septum was purged with air $(20 \mathrm{~mL})$, and a solution of 6-8 mg (12-16 $\mu \mathrm{mol})$ of boronic ester $(R)-7$ and $14 \mathrm{mg}$ $(21 \mu \mathrm{mol})$ of $\mathrm{Cu}(\mathrm{OTf})_{2}(\mathrm{py})_{4}$ in $0.3 \mathrm{~mL}$ of dry dimethylacetamide was added. The resulting solution was stirred at $120^{\circ} \mathrm{C}$ for $20 \mathrm{~min}$ and diluted with $1.5 \mathrm{~mL}$ of acetonitrile/ $\mathrm{H}_{2} \mathrm{O}$ (1:1). On addition of $0.4 \mathrm{~mL}$ of aqueous $\mathrm{NaOH}(10 \mathrm{M}, 400 \mathrm{mg} / \mathrm{mL})$, the mixture was stirred at $90^{\circ} \mathrm{C}$ for $15 \mathrm{~min}$. The final product was purified by semipreparative highperformance liquid chromatography, and the final product was formulated with $5 \%$ ethanol in saline. This vehicle was used for all biologic experiments. The identities of the radioligands were confirmed by coinjection with corresponding nonradioactive reference compounds. ${ }^{11} \mathrm{C}$-labeled probes were synthesized using the same procedure as previously reported for ${ }^{11} \mathrm{C}-\mathrm{Me}-\mathrm{NB} 1$ (15).

\section{In Vitro Autoradiography}

Rodent brain tissue was embedded in Tissue-Tek optimal-cuttingtemperature compound (Sakura Finetek ). Coronal rat and mouse brain sections of $10-\mu \mathrm{m}$ thickness were prepared on a cryostat (Cryo-Star HM $560 \mathrm{MV}$; Microm/Thermo Scientific). The tissue sections were mounted to SuperFrost Plus slides (Menzel) and stored at $-20^{\circ} \mathrm{C}$ until further use. Before the autoradiography experiments, brain slices were initially thawed for $15 \mathrm{~min}$ on ice and subsequently preconditioned for $10 \mathrm{~min}$ at $0^{\circ} \mathrm{C}$ in assay buffer $1(\mathrm{pH} 7.4)$ containing 4-(2-hydroxyethyl)-1-piperazineethanesulfonic acid (30 mM, $7.1 \mathrm{mg} / \mathrm{mL}), \mathrm{MgCl}_{2}$ (0.56 mM, $0.05 \mathrm{mg} / \mathrm{mL}), \mathrm{NaCl}(110 \mathrm{mM}, 6.4 \mathrm{mg} / \mathrm{mL}), \mathrm{CaCl}_{2}$ (3.3 mM, 0.4 mg/mL), $\mathrm{KCl}(5 \mathrm{mM}, 0.4 \mathrm{mg} / \mathrm{mL})$, and $0.1 \%$ fatty acid-free bovine serum albumin. On drying, the tissue sections were incubated with $1 \mathrm{~mL}$ of the respective radioligand $(3 \mathrm{nM})$ for $15 \mathrm{~min}$ at $21^{\circ} \mathrm{C}$ in a humidified chamber. For $\sigma_{1} \mathrm{R}$ blockade, $1 \mu \mathrm{M} \mathrm{SA} 4503$ (half-maximal inhibitory concentration [ $\left.\mathrm{IC}_{50}\right]$ for $\sigma_{1} \mathrm{R}, 17.4 \mathrm{nM}(20)$ ), fluspidine (inhibition constant for $\sigma_{1} \mathrm{R}, 0.59 \mathrm{nM}(21)$ ), or (+)-pentazocine $\left(\mathrm{IC}_{50}\right.$ for $\sigma_{1} \mathrm{R}, 13.7 \mathrm{nM}(20)$ ) was added to the radiotracer solution. For GluN2B blockade, $1 \mu \mathrm{M}$ CERC-301 ( $\mathrm{IC}_{50}$ for GluN2B, $3.6 \mathrm{nM}(22)$ ), EVT $101\left(\right.$ IC $_{50}$ for GluN2B, $12 \mathrm{nM}(23)$ ), or CP101,606 ( IC $_{50}$ for GluN2B, $11 \mathrm{nM}(24)$ ) was added to the radiotracer solution. The brain slices were washed for $5 \mathrm{~min}$ in assay buffer 1 and further washed twice $3 \mathrm{~min}$ in assay buffer 2 (assay buffer 1 without bovine serum albumin). Tissue sections were dipped twice in distilled water, were subsequently dried, and were exposed to a phosphor imager plate (Fuji) for $30 \mathrm{~min}$. The films were scanned in a BAS5000 reader (Fuji), and images were generated using AIDA software (version 4.50.010; Raytest Isotopenmessgeräte $\mathrm{GmbH}$ ).

\section{Metabolite Study}

Wistar rats were injected with $242-704 \mathrm{MBq}(14.8-27.5 \mathrm{nmol} / \mathrm{kg})$ of $(R)-{ }^{18}$ F-OF-Me-NB1. Samples of the brain extracts at predefined times $(15,30$, and $60 \mathrm{~min})$ and plasma $(5,15,30,45$, and $60 \mathrm{~min})$ were obtained and analyzed by radio-ultra-performance liquid chromatography (UPLC) and radio-thin-layer chromatography.

\section{Ex Vivo Biodistribution}

Eight male Wistar rats (4 baseline and 4 blockade animals) were administered $(R)-{ }^{18} \mathrm{~F}-\mathrm{OF}-\mathrm{Me}-\mathrm{NB} 1(5-16 \mathrm{MBq}, 2.0-4.9 \mathrm{nmol} / \mathrm{kg})$ via tail-vein injection and sacrificed by decapitation under isoflurane anesthesia at $30 \mathrm{~min}$ after injection. For blockade experiments, a $2 \mathrm{mg} / \mathrm{kg}$ dose of eliprodil in a vehicle of aqueous glucose $(5 \%), \mathrm{NaCl}(0.45 \%)$, and citric acid $(1 \mathrm{mM})$ was injected shortly before tracer administration.

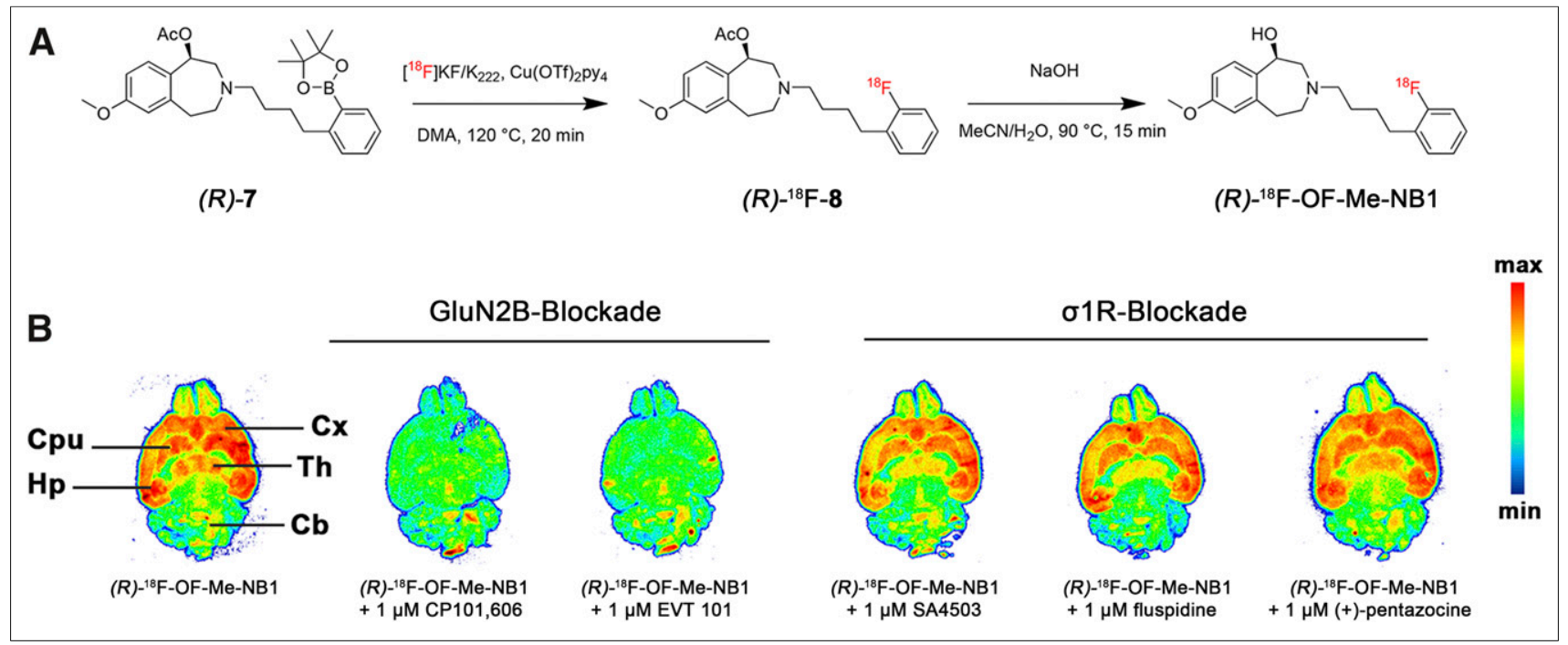

FIGURE 3. (A) Synthesis of $(R)-{ }^{18} \mathrm{~F}-\mathrm{OF}-\mathrm{Me}-\mathrm{NB} 1$ using copper-mediated radiofluorination and subsequent deacetylation under basic conditions. (B) Representative in vitro autoradiographic blocker screening in rat brain sections with GluN2B ligands $\left(C P 101,606, E V T\right.$ 101) and $\sigma_{1} R$ ligands (SA4503, fluspidine, (+)-pentazocine). $\mathrm{Cb}=$ cerebellum; $\mathrm{CPu}=$ caudate putamen (striatum); $\mathrm{Cx}=$ cortex; $\mathrm{Hp}=$ hippocampus; $\mathrm{Th}=$ thalamus. 


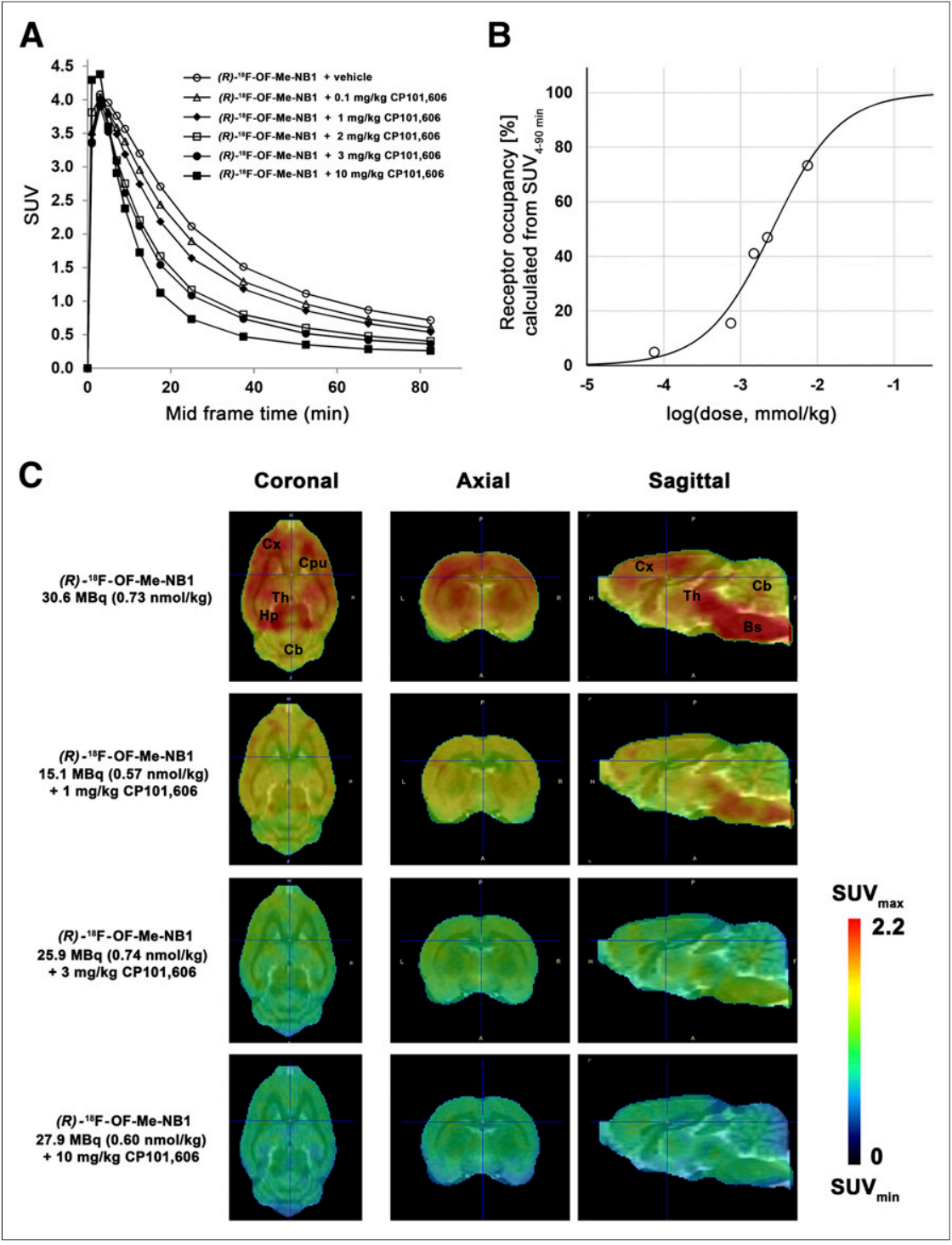

FIGURE 4. Dose-dependent blocking of $(R)-{ }^{18} \mathrm{~F}-\mathrm{OF}-\mathrm{Me}-\mathrm{NB} 1$ binding by GluN2B antagonist CP101,606 in Wistar rat brain in vivo and respective calculated receptor occupancy. (A) Timeactivity curves for baseline and blockade experiments with escalating injected doses of CP101,606 (0.1-10 mg/kg) are presented as SUVs. (B) Receptor occupancy for each CP101,606 dose calculated from area under curve of SUVs $\left(S V_{0-90} \mathrm{~min}\right)$. (C) PET images of rat brain superimposed on PMOD MRI template under baseline and blockade conditions with GluN2B antagonist $\mathrm{CP} 101,606$. Images were averaged from 0 to $90 \mathrm{~min}$ after injection. $\mathrm{Bs}=$ brain stem; $\mathrm{Cb}=$ cerebellum; $\mathrm{CPu}=$ caudate putamen (striatum); $\mathrm{Cx}=$ cortex; $\mathrm{Hp}=$ hippocampus; $\mathrm{Th}=$ thalamus. obtained data were reconstructed in user-defined time frames with a voxel size of $0.3875 \times$ $0.3875 \times 0.775 \mathrm{~mm}$ as previously described by our group (15). Time-activity curves were generated by PMOD (version 3.7; PMOD Technologies) with predefined regions of interest. The results are given as SUVs. Receptor occupancy evaluations were performed using the area under the curve of the SUVs calculated from 4 to $90 \mathrm{~min}$ as previously reported by our group (15).

\section{Statistical Analysis}

An independent 2-tailed Student test assuming normal distribution of the dataset was used to calculate statistical probability values.

\section{RESULTS}

\section{Chemistry and Binding Affinity}

Reference compounds, OF-Me-NB1 and PF-Me-NB1, were obtained in chemical yields of $41 \%$ and $49 \%$, respectively (Supplemental Fig. 1). By competitive binding assays with ${ }^{3} \mathrm{H}$-ifenprodil and rat brain homogenates, inhibition constants for the GluN2B binding site of $37 \mathrm{nM}$ ((rac)-OFMe-NB1), $56 \mathrm{nM}$ ((rac)-PF-Me-NB1), and $4 \mathrm{nM}((R)$-OF-Me-NB1) were determined. Applying the same competitive binding assay with $(+)-{ }^{3} \mathrm{H}$-pentazocine and rat brain homogenates, inhibition constants obtained for $\sigma_{1} \mathrm{R}$ were $12 \mathrm{nM}, 32 \mathrm{nM}$, and $100 \mathrm{nM}$ for (rac)-PF-Me-NB1, (rac)-OF-Me-NB1, and $(R)-\mathrm{OF}-\mathrm{Me}-\mathrm{NB} 1$, respectively. The respective phenolic precursors, OF-NB1 and $\mathrm{PF}-\mathrm{NB} 1$, were obtained by treatment of OF-Me-NB1 and PF-Me-NB1 with $\mathrm{BBr}_{3}$ in $41 \%$ and $53 \%$ chemical yields, respectively. The synthetic strategy, chiral separations, and circular dichroism results are described in Supplemental Figures 2 and 3. The multistep synthesis of boronic pinacol ester precursor 7 for radiofluorination is provided in Supplemental Figure 4.

\section{${ }^{11} \mathrm{C}$ Labeling of PF- and OF-Me-NB1 and Preliminary In Vitro Autoradiography}

Organs were dissected and weighed, and radioactivity was measured in a $\gamma$-counter (Perkin Elmer). Biodistribution results are reported as percentage normalized injected dose per gram of tissue.

\section{In Vivo PET and Dose-Response Studies}

$\mathrm{CD} 1$ mice, $\sigma_{1} \mathrm{R}-\mathrm{KO}$ mice, and Wistar rats were anesthetized with isoflurane and scanned in a PET/CT scanner (Super Argus; Sedecal) on tail-vein injection of $(R)-{ }^{18} \mathrm{~F}-\mathrm{OF}-\mathrm{Me}-\mathrm{NB} 1$ (15-38 MBq, $0.6-1.7$ $\mathrm{nmol} / \mathrm{kg}$ [rats, scan time of 0-90 $\mathrm{min}$ ], or 3-16 MBq, 4.3-19.7 nmol/kg [mice, scan time of 1-90 min]). For anatomic orientation, PET scans were followed by CT scans. For blockade studies, a $2 \mathrm{mg} / \mathrm{kg}$ dose of eliprodil was injected into $\mathrm{CD} 1$ and $\sigma_{1} \mathrm{R}-\mathrm{KO}$ mice a few seconds before the radioligand. Dose-response and receptor occupancy studies in Wistar rats were conducted by tail-vein injection of different doses $(0.1,1,2,3$, and $10 \mathrm{mg} / \mathrm{kg}$ ) of CP101,606 shortly before tracer administration. The
$(R)$ - and $(S)-{ }^{11} \mathrm{C}-\mathrm{PF}-\mathrm{Me}-\mathrm{NB} 1$, as well as $(R)$ - and $(S)-{ }^{11} \mathrm{C}-\mathrm{OF}-$ $\mathrm{Me}-\mathrm{NB} 1$, were obtained by chiral resolution of the respective racemic phenolic precursors followed by ${ }^{11} \mathrm{C}$ labeling using ${ }^{11} \mathrm{C}$ MeI. The radiochemical yields ranged from $7 \%$ to $36 \%$ (decaycorrected, calculated from the ${ }^{11} \mathrm{C}-\mathrm{CO}_{2}$ starting activity), with molar activities between 54 and $220 \mathrm{GBq} / \mu \mathrm{mol}$. The radiochemical purity was greater than $99 \%$ for all 4 radioligands. Introduction of ${ }^{18} \mathrm{~F}$ at the para position of the phenyl moiety resulted in a homogeneous binding across all brain regions on coronal rat brain sections for both enantiomeric forms (Fig. 2A). In contrast, the introduction of fluorine at the ortho position resulted in a high and specific accumulation of the $(R)$-enantiomer in GluN2B-rich forebrain regions (Fig. 2B). To further investigate the underlying causes for the differences in the regional accumulation of the 
4 different radioligands, we performed autoradiography studies on mouse brain sections using GluN2B (specificity assessment) and $\sigma_{1} \mathrm{R}$ ligands (selectivity assessment) as blockers. We found that both para-fluorinated enantiomers $(R)$ - and $(S)-{ }^{11} \mathrm{C}-\mathrm{PF}-\mathrm{Me}-\mathrm{NB} 1$ showed considerable $\sigma_{1} \mathrm{R}$ binding (Supplemental Figs. 5 and 6). Remarkably, the ortho-fluorinated enantiomers $(R)$ - and $(S)-{ }^{11} \mathrm{C}-\mathrm{OF}-\mathrm{Me}-$ NB1 revealed an entirely different receptor binding behavior (Fig. 2C). Although $(R)-{ }^{11} \mathrm{C}-\mathrm{OF}-\mathrm{Me}-\mathrm{NB} 1$ exhibited GluN2B specificity and selectivity over the $\sigma_{1} \mathrm{R},(S)-{ }^{11} \mathrm{C}-\mathrm{OF}-\mathrm{Me}-\mathrm{NB} 1$ was found to bind predominantly to the $\sigma_{1} \mathrm{R}$. Consequently, $(R)$-OF-Me-NB1 was selected for radiofluorination and further preclinical evaluation.

\section{Radiofluorination and In Vitro Autoradiography with (R)-11C-OF-Me-NB1}

To accomplish the radiofluorination, aryl boronic ester precursor 7 was synthesized as shown in Supplemental Figure 4. The radiosynthesis presented in Figure 3A was performed according to the procedure recently reported by Preshlock et al., but with slight modifications (19). (R)- ${ }^{18} \mathrm{~F}-\mathrm{OF}-\mathrm{Me}-\mathrm{NB} 1$ was obtained in $13 \%-$ $25 \%$ radiochemical yields $(n=8$, based on high-performance liquid chromatography analysis of the crude product), and radiochemical purity was more than $99 \%$. Molar activities ranged from 61 to $168 \mathrm{GBq} / \mu \mathrm{mol}$ at the end of the synthesis. Enantiopurity of the radioligand was assessed by chiral high-performance liquid chromatography. A $\log D_{7.4}$ value of $2.2 \pm 0.1(n=4)$ was obtained using the shake-flask method. $(R)-{ }^{18} \mathrm{~F}-\mathrm{OF}-\mathrm{Me}-\mathrm{NB} 1$ revealed a high selectivity for the GluN2B-expressing cortex, striatum, thalamus, and hippocampus over the GluN2B-deficient cerebellum on rat brain autoradiograms (Fig. 3B). Blockade studies were conducted with the $\sigma_{1} \mathrm{R}$ ligands (+)-pentazocine, SA4503, and fluspidine to elucidate their ability to compete
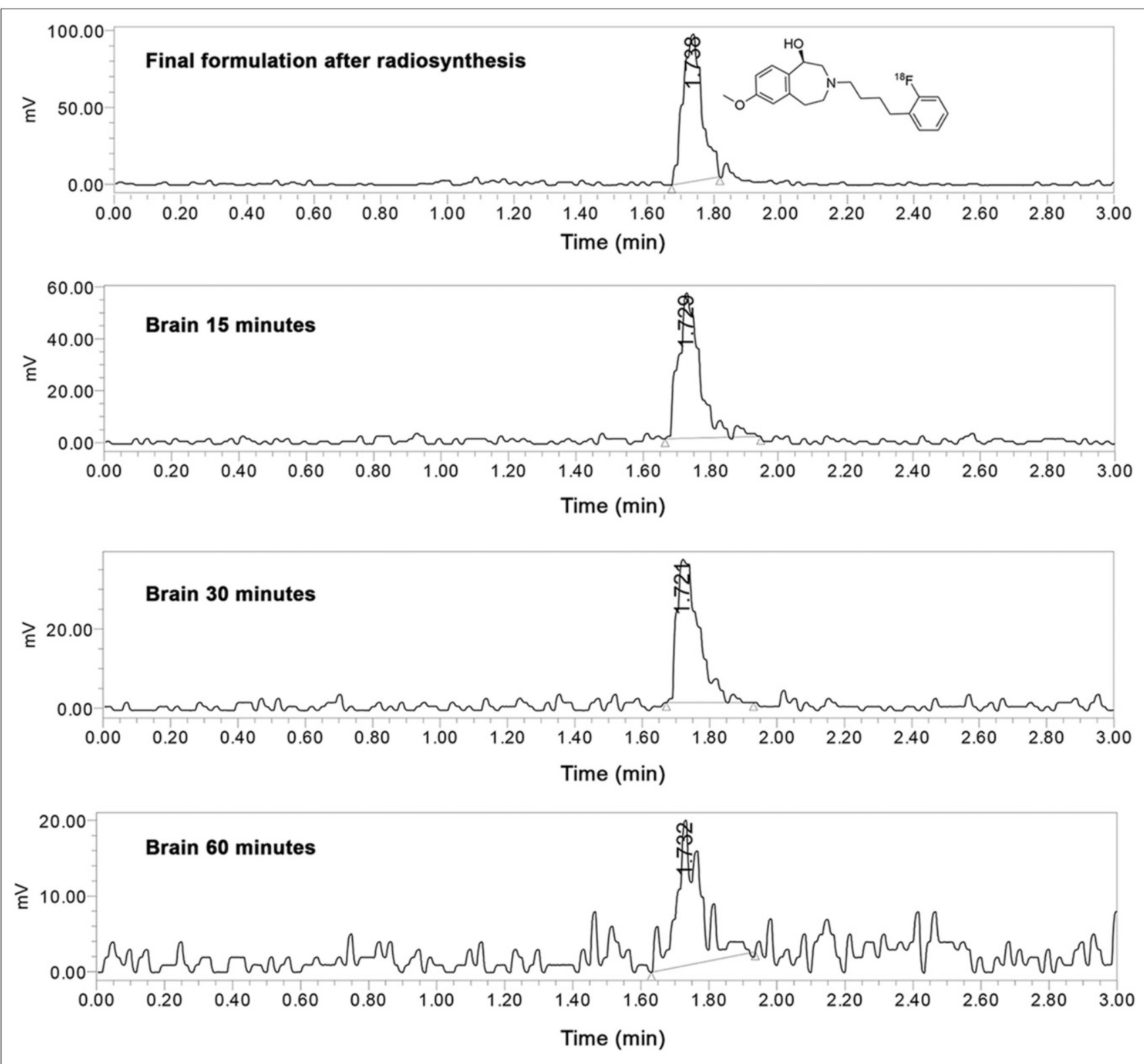

FIGURE 5. Radio-UPLC analysis of Wistar rat brain extracts. Final tracer formulation after radiosynthesis is depicted, as well as brain samples at 15,30 , and 60 min after injection. 
with $(R)-{ }^{18} \mathrm{~F}-\mathrm{OF}-\mathrm{Me}-\mathrm{NB} 1$ binding. To confirm GluN2B specificity, the GluN2B antagonists EVT 101 and CP-101,606 were included in the same experiment. The results of the autoradiography screening with the various ligands confirmed the GluN2B specificity of $(R)-{ }^{18} \mathrm{~F}-\mathrm{OF}-\mathrm{Me}-\mathrm{NB} 1$, as well as its in vitro selectivity over $\sigma_{1} \mathrm{R}$.

\section{Dose-Dependence and Receptor Occupancy Studies}

The clinical efficacy of the GluN2B-selective antagonist CP101,606 has been demonstrated in clinical trials $(4,16,17)$. Applying $(R)-{ }^{18} \mathrm{~F}-\mathrm{OF}-\mathrm{Me}-\mathrm{NB} 1$, we assessed the receptor occupancy of $\mathrm{CP} 101,606$ in the rat brain at a dose ranging from 0.1 to 10 $\mathrm{mg} / \mathrm{kg}$. A consistent dose-dependent reduction of the SUVs with escalating CP101,606 doses was observed (Fig. 4A). SUVs were further used to determine in vivo receptor occupancy. The CP101,606 dose required for 50\% receptor occupancy was 8.3 $\mu \mathrm{mol} / \mathrm{kg}$ (Fig. 4B), and the lowest and highest blocker doses showed $4.9 \%$ and $73.3 \%$ receptor occupancy, respectively. PET images confirming the dose-dependent target engagement are depicted in Figure 4C.

\section{Metabolite Studies}

To assess its metabolic stability, $(R)-{ }^{18} \mathrm{~F}-\mathrm{OF}-\mathrm{Me}-\mathrm{NB} 1$ was injected into male Wistar rats, and plasma radioactivity at $5,15,30$, 45 , and $60 \mathrm{~min}$ after injection, as well as brain extracts at 15, 30, and $60 \mathrm{~min}$ after injection, were analyzed by radio-UPLC. The analysis revealed the presence of intact tracer in the brain at 15 , 30 , and $60 \mathrm{~min}$ after injection and the absence of radiometabolites up to $30 \mathrm{~min}$ after injection (Fig. 5). The chromatogram of the sample obtained at $60 \mathrm{~min}$ after injection was rather noisy and did not allow the detection of potential radiometabolites in the brain.

Plasma samples revealed the presence of 2 polar radiometabolites. The fractions of intact parent of total radioactivity found in the plasma at $0,5,15,30,45$, and $60 \mathrm{~min}$ after injection are summarized in Table 1. At the last measured time point of $60 \mathrm{~min}$ after injection, the fraction of intact tracer was $45 \%$.

\section{Brain Time-Activity Curves and Biodistribution}

GluN2B specificity of $(R)-{ }^{18} \mathrm{~F}-\mathrm{OF}-\mathrm{Me}-\mathrm{NB} 1$ was demonstrated by PET in male Wistar rats on tail-veil injection of the radioligand with the GluN2B antagonists CP101,606 or eliprodil (Fig. 6). Timeactivity curves were generally higher in the cortex, hippocampus, striatum, and thalamus than in the cerebellum. These findings were confirmed by ex vivo autoradiography (Supplemental Fig. 7). On injection of CP101,606 or eliprodil (blockers were injected

TABLE 1

Metabolite Study of $(R)^{-18} \mathrm{~F}-\mathrm{OF}-\mathrm{Me}-\mathrm{NB} 1$ in Male Wistar Rats

\begin{tabular}{lcc}
\hline Time $(\min )$ & $(R))^{-18}$ F-OF-Me-NB1 $(\%)$ & Radiometabolites $(\%)$ \\
\hline 0 & 100 & 0 \\
5 & 86 & 14 \\
15 & 76 & 24 \\
30 & 71 & 29 \\
45 & 52 & 48 \\
60 & 45 & 55
\end{tabular}

Fractions of intact parent tracer and radiometabolites in plasma are depicted as percentage of total radioactivity. intravenously shortly before the tracer), a blocking effect was observed in all brain regions; however, the reduction of radioactivity accumulation was most pronounced in the GluN2B-rich regions such as the cortex, hippocampus, striatum, and thalamus. Ex vivo biodistribution experiments on male Wistar rats were conducted at $30 \mathrm{~min}$ after injection. The time point was based on the in vivo specificity deduced from the time-activity curves of baseline and blockade PET scans with the GluN2B antagonists CP101,606 and eliprodil (Fig. 6). We found a heterogeneous uptake of the radioligand in different brain regions, and radioligand uptake was significantly higher in the GluN2B-expressing regions than in the cerebellum: the cortex-to-cerebellum ratio was $1.37(P=$ $0.001)$, the striatum-to-cerebellum ratio was $1.30(P=0.002)$, the hippocampus-to-cerebellum ratio was $1.36(P=0.003)$, and the thalamus-to-cerebellum ratio was $1.33(P=0.007)$. The ex vivo biodistribution results are summarized in Supplemental Tables 1 and 2. On ex vivo biodistribution and PET imaging studies, the Wistar rat brain stem showed a considerable radioligand uptake, which was efficiently blocked by CP101,606 and eliprodil.

\section{PET Experiments with $\sigma_{1}$ R-KO and Wild-Type Mice}

Dynamic PET scans were performed with $\sigma_{1} \mathrm{R}-\mathrm{KO}$ and wildtype mice to exclude $\sigma_{1} \mathrm{R}$ binding of $(R)-{ }^{18} \mathrm{~F}-\mathrm{OF}-\mathrm{Me}-\mathrm{NB} 1$ in vivo. PET images and time-activity curves of radioligand uptake in the brain are presented in Figure 7. There was no difference in the time-activity curves of $\sigma_{1} \mathrm{R}-\mathrm{KO}$ mice and the respective wild-type animals (Fig. 7B), indicating that $(R)-{ }^{18} \mathrm{~F}-\mathrm{OF}-\mathrm{Me}-\mathrm{NB} 1$ brain uptake is independent of the $\sigma_{1} \mathrm{R}$ and, thus, confirming the selectivity of binding of $(R)-{ }^{18} \mathrm{~F}-\mathrm{OF}-\mathrm{Me}-\mathrm{NB} 1$ to GluN2B receptors over $\sigma_{1} \mathrm{R}$ in vivo. In both $\sigma_{1} \mathrm{R}-\mathrm{KO}$ and wild-type mice, injection of a 2 $\mathrm{mg} / \mathrm{kg}$ dose of the GluN2B antagonist eliprodil resulted in a lower brain uptake and a faster washout of $(R)-{ }^{18} \mathrm{~F}-\mathrm{OF}-\mathrm{Me}-\mathrm{NB} 1$, indicating specific binding of $(R)-{ }^{18} \mathrm{~F}-\mathrm{OF}-\mathrm{Me}-\mathrm{NB} 1$ to GluN2B receptors in the mouse brain.

\section{DISCUSSION}

Given the implication of GluN2B-containing NMDA receptors in various neurologic disorders and the lack of a useful GluN2Bspecific PET probe, our research group has dedicated concerted efforts to address this unmet medical need and recently succeeded in developing a suitable ${ }^{11} \mathrm{C}$-labeled GluN2B PET radioligand, ${ }^{11} \mathrm{C}-\mathrm{Me}-\mathrm{NB} 1$ (15). The short physical half-life of ${ }^{11} \mathrm{C}$, however, has prompted us to design analogs that are suitable for ${ }^{18} \mathrm{~F}$ labeling. In particular, a radiofluorinated derivative would enable a wider use through satellite distribution to facilities lacking the necessary radiochemistry infrastructure. PF-Me-NB1 and OFMe-NB1 were synthesized in good chemical yields, and their binding affinities to the rat GluN2B-containing NMDA receptor were shown to be comparable to the $40 \mathrm{nM}$ inhibition constant of lead compound Me-NB1 (15). Because of the differences observed in autoradiography experiments with the enantiomers of ${ }^{11} \mathrm{C}-\mathrm{Me}$ $\mathrm{NB} 1$, we initially radiolabeled the 4 candidate compounds, $(R)$-PF-Me-NB1, $(S)$-PF-Me-NB1, $(R)$-OF-Me-NB1, and $(S)$-OF$\mathrm{Me}-\mathrm{NB} 1$, with ${ }^{11} \mathrm{C}$ and assessed their in vitro performance using autoradiography with the aim of finding a suitable GluN2B-specific and -selective candidate for radiofluorination. Autoradiograms of the rodent brain indicated that the introduction of fluorine at the para position of the aryl moiety led to a remarkable reduction in selectivity over the $\sigma_{1} R$, possibly because of direct interactions of the fluorine atom with the $\sigma_{1} R$. When fluorine was introduced at the 


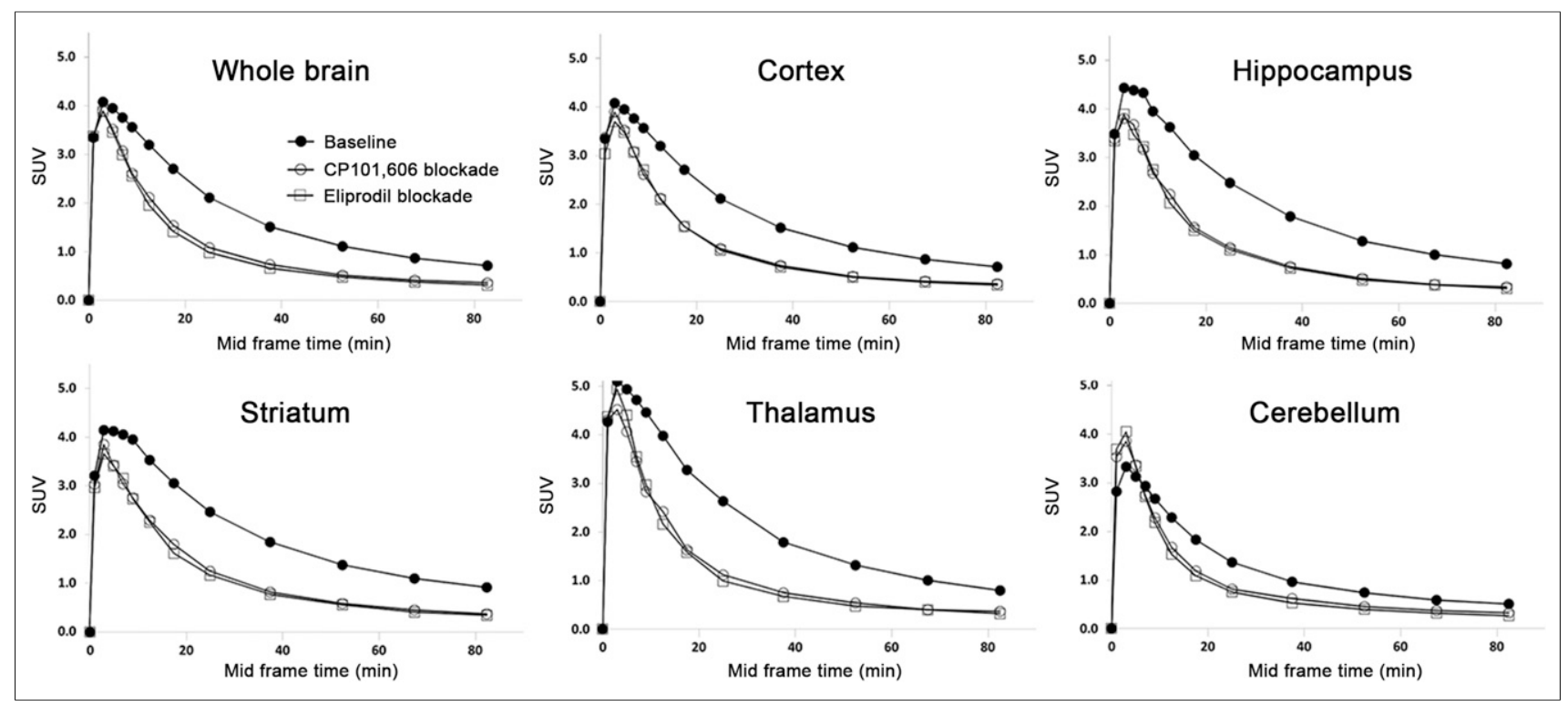

FIGURE 6. Time-activity curves in different brain regions of Wistar rat are presented as SUVs. Specificity of $(R)-{ }^{18} \mathrm{~F}-\mathrm{OF}-\mathrm{Me}-\mathrm{NB} 1$ binding was confirmed by injection of GluN2B antagonists CP101,606 (3 mg/kg) and eliprodil (2 mg/kg) shortly before radioligand injection. One rat was scanned for each condition.

ortho position, selectivity over the $\sigma_{1} \mathrm{R}$ was restored, thereby underlining the relevance of the fluorine position within the aromatic ring and supporting the hypothesis of direct fluorine engagement (e.g., via hydrogen bond) in the case of PF-Me-NB1. The promising autoradiography results with $(R)-{ }^{11} \mathrm{C}-\mathrm{OF}-\mathrm{Me}-\mathrm{NB} 1$ prompted us to radiolabel $(R)-\mathrm{OF}-\mathrm{Me}-\mathrm{NB} 1$ with ${ }^{18} \mathrm{~F}$. Using a boronic ester precursor, $(R)-{ }^{18} \mathrm{~F}-\mathrm{OF}-\mathrm{Me}-\mathrm{NB} 1$ was obtained in moderate radiochemical yields, high molar activities, and excellent radiochemical purities. The radiofluorinated probe outperformed ${ }^{11} \mathrm{C}-\mathrm{Me}-\mathrm{NB} 1$ with regard to forebrain selectivity by in vitro autoradiography (15). In accordance with our previous report on ${ }^{11} \mathrm{C}-\mathrm{Me}-\mathrm{NB} 1$, we observed a considerable binding of $(R)-{ }^{18} \mathrm{~F}-\mathrm{OF}-$ Me-NB1 to Wistar rat brain stem in vivo, and this binding was abolished by the GluN2B antagonists CP101,606 and eliprodil. Whether this uptake is related to GluN2B or alternative GluN subtypes as suggested for ${ }^{11} \mathrm{C}-\mathrm{Me}-\mathrm{NB} 1$ remains to be further investigated. Off-target binding to the $\sigma_{1} \mathrm{R}$ was excluded in vivo by PET imaging with $\sigma_{1} \mathrm{R}-\mathrm{KO}$ mice. Calculated time-activity curves did not reveal any differences in the brain uptake of $\sigma_{1} \mathrm{R}-\mathrm{KO}$ and the respective wild-type mice $(n=3)$, confirming that the

\section{A}

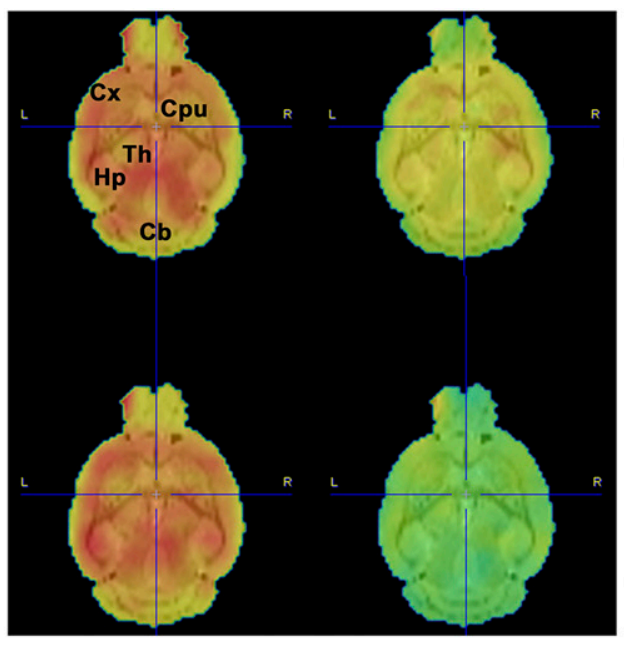

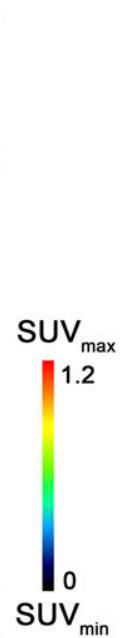

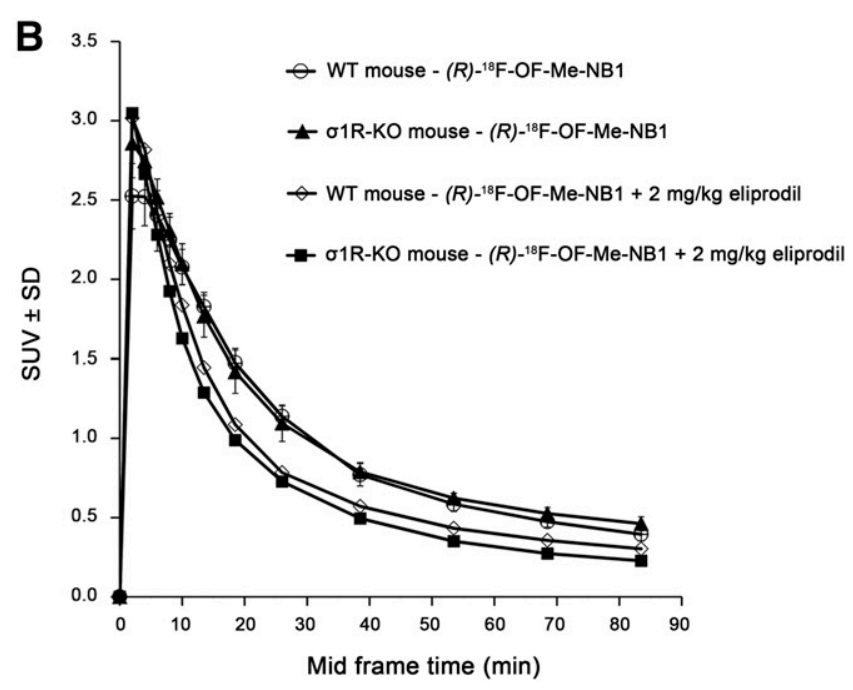

FIGURE 7. PET study of $(R)-{ }^{18} \mathrm{~F}-\mathrm{OF}-\mathrm{Me}-\mathrm{NB} 1$ in $\sigma_{1} \mathrm{R}-\mathrm{KO}$ and wild-type (WT) mice. For blockade experiments, $2 \mathrm{mg} / \mathrm{kg}$ dose of commercially available GluN2B antagonist eliprodil was used. (A) Coronal PET images, averaged from 1 to 90 min after injection, superimposed on MRI template (PMOD). Shown are WT baseline (upper left), WT eliprodil blockade (upper right), $\sigma_{1} R-K O$ baseline (lower left), and $\sigma_{1} R-K O$ eliprodil blockade (lower right). (B) Brain time-activity curves are presented as SUV \pm SD. Baseline scans were performed on 3 mice and blockade scans on 1 mouse. $\mathrm{Cb}=$ cerebellum; $\mathrm{CPu}=$ caudate putamen (striatum); $\mathrm{Cx}=$ cortex; $\mathrm{Hp}=$ hippocampus; $\mathrm{Th}=$ thalamus. 
accumulation of $(R)-{ }^{18} \mathrm{~F}-\mathrm{OF}-\mathrm{Me}-\mathrm{NB} 1$ is independent of the $\sigma_{1} \mathrm{R}$. Finally, the utility of $(R)-{ }^{18} \mathrm{~F}-\mathrm{OF}-\mathrm{Me}-\mathrm{NB} 1$ in studying GluN2B target engagement in vivo was demonstrated by receptor occupancy studies with CP101,606, the only existing GluN2B antagonist with documented clinical efficacy $(4,17,25)$. $(R)-{ }^{18} \mathrm{~F}-\mathrm{OF}-\mathrm{Me}-\mathrm{NB} 1$ is the first radiofluorinated probe that can be successfully used to visualize interactions between drug candidates and the GluN2B-carrying NMDA receptor in vivo. Clinical availability of such a PET radioligand will not only provide the possibility of predicting therapeutic doses but also help to explain why GluN2B antagonists fail to demonstrate clinical efficacy. It remains to be elucidated in future studies whether the ${ }^{11} \mathrm{C}$ version, $(R)-{ }^{11} \mathrm{C}-\mathrm{OF}-\mathrm{Me}-\mathrm{NB} 1$, will show in vivo characteristics similar to those of $(R)-{ }^{18} \mathrm{~F}-\mathrm{OF}-\mathrm{Me}-\mathrm{NB} 1$.

\section{CONCLUSION}

We have successfully developed $(R)-{ }^{18} \mathrm{~F}-\mathrm{OF}-\mathrm{Me}-\mathrm{NB} 1$, which is, to our knowledge, the first radiofluorinated radioligand for imaging GluN2B subunits of the NMDA receptor complex. The data suggest that $(R)-{ }^{18} \mathrm{~F}-\mathrm{OF}-\mathrm{Me}-\mathrm{NB} 1$ has promising imaging attributes and great potential for receptor occupancy studies with GluN2B drugs. In addition, $(R)-{ }^{18} \mathrm{~F}-\mathrm{OF}-\mathrm{Me}-\mathrm{NB} 1$ could be a future tool for imaging GluN2B receptors in humans with brain diseases in which the GluN2B receptors have been implicated.

\section{DISCLOSURE}

This project was supported by grant 310030E-160403/1 from the Swiss National Science Foundation. No other potential conflict of interest relevant to this article was reported.

\section{ACKNOWLEDGMENTS}

We thank Bruno Mancosu for providing technical assistance with the carbon-11 module and Dr. Jose Miguel Vela for providing the $\sigma_{1} \mathrm{R}-\mathrm{KO}$ mice.

\section{REFERENCES}

1. Mehta A, Prabhakar M, Kumar P, Deshmukh R, Sharma PL. Excitotoxicity: bridge to various triggers in neurodegenerative disorders. Eur J Pharmacol. 2013;698:6-18.

2. Kalia LV, Kalia SK, Salter MW. NMDA receptors in clinical neurology: excitatory times ahead. Lancet Neurol. 2008;7:742-755.

3. Hurley LL, Tizabi Y. Neuroinflammation, neurodegeneration and depression. Neurotox Res. 2013;23:131-144.

4. Nutt JG, Gunzler SA, Kirchhoff T, et al. Effects of a NR2B selective NMDA glutamate antagonist, CP-101,606, on dyskinesia and parkinsonism. Mov Disord. 2008;23:1860-1866.

5. Di X, Bullock R, Watson J, et al. Effect of CP101,606, a novel NR2B subunit antagonist of the N-methyl-D-aspartate receptor, on the volume of ischemic brain damage off cytotoxic brain edema after middle cerebral artery occlusion in the feline brain. Stroke. 1997;28:2244-2251.
6. Miller $\mathrm{OH}$, Yang L, Wang CC, et al. GluN2B-containing NMDA receptors regulate depression-like behavior and are critical for the rapid antidepressant actions of ketamine. eLife. 2014;3:e03581.

7. Layer RT, Popik P, Olds T, Skolnick P. Antidepressant-like actions of the polyamine site NMDA antagonist, eliprodil (SL-82.0715). Pharmacol Biochem Behav. 1995;52:621-627.

8. Buckner R L. The cerebellum and cognitive function: 25 years of insight from anatomy and neuroimaging. Neuron. 2013;80:807-815.

9. Kemp JA, McKernan RM. NMDA receptor pathways as drug targets. Nat Neurosci. 2002;5(suppl):1039-1042.

10. Tajima N, Karakas E, Grant T, et al. Activation of NMDA receptors and the mechanism of inhibition by ifenprodil. Nature. 2016;534:63-68.

11. Ibrahim L, Diaz Granados N, Jolkovsky L, et al. A randomized, placebo-controlled, crossover pilot trial of the oral selective NR2B antagonist MK-0657 in patients with treatment-resistant major depressive disorder. J Clin Psychopharmacol. 2012;32:551-557.

12. Addy C, Assaid C, Hreniuk D, et al. Single-dose administration of MK-0657, an NR2B-selective NMDA antagonist, does not result in clinically meaningful improvement in motor function in patients with moderate Parkinson's disease. J Clin Pharmacol. 2009;49:856-864.

13. Herring WJ, Assaid C, Budd K, et al. A phase $\mathrm{Ib}$ randomized controlled study to evaluate the effectiveness of a single-dose of the NR2B selective N-methylD-aspartate antagonist MK-0657 on levodopa-induced dyskinesias and motor symptoms in patients with Parkinson disease. Clin Neuropharmacol. 2017;40:255-260.

14. Simon GM, Niphakis MJ, Cravatt BF. Determining target engagement in living systems. Nat Chem Biol. 2013;9:200-205.

15. Krämer SD, Betzel T, Mu L, et al. Evaluation of ${ }^{11} \mathrm{C}-\mathrm{Me}-\mathrm{NB} 1$ as a potential PET radioligand for measuring GluN2B-containing NMDA receptors, drug occupancy, and receptor cross talk. J Nucl Med. 2018;59:698-703.

16. Bullock MR, Merchant RE, Carmack CA, et al. An open-label study of CP101,606 in subjects with a severe traumatic head injury or spontaneous intracerebral hemorrhage. Ann N Y Acad Sci. 1999;890:51-58.

17. Preskorn SH, Baker B, Kolluri S, Menniti FS, Krams M, Landen JW. An innovative design to establish proof of concept of the antidepressant effects of the NR2B subunit selective N-methyl-D-aspartate antagonist, CP-101,606, in patients with treatment-refractory major depressive disorder. J Clin Psychopharmacol. 2008;28:631-637.

18. Tewes B, Frehland B, Schepmann D, Schmidtke KU, Winckler T, Wunsch B. Design, synthesis, and biological evaluation of 3-benzazepin-1-ols as NR2Bselective NMDA receptor antagonists. ChemMedChem. 2010;5:687-695.

19. Preshlock S, Calderwood S, Verhoog S, et al. Enhanced copper-mediated ${ }^{18} \mathrm{~F}$ fluorination of aryl boronic esters provides eight radiotracers for PET applications. Chem Commun (Camb). 2016;52:8361-8364.

20. Matsuno K, Nakazawa M, Okamoto K, Kawashima Y, Mita S. Binding properties of SA4503, a novel and selective sigma 1 receptor agonist. Eur J Pharmacol. 1996;306:271-279.

21. Fischer S, Wiese C, Maestrup EG, et al. Molecular imaging of sigma receptors: synthesis and evaluation of the potent $\sigma_{1}$ selective radioligand $\left[{ }^{18} \mathrm{~F}\right]$ fluspidine. Eur J Nucl Med Mol Imaging. 2011;38:540-551.

22. Garner R, Gopalakrishnan S, McCauley JA, et al. Preclinical pharmacology and pharmacokinetics of CERC-301, a GluN2B-selective N-methyl-D-aspartate receptor antagonist. Pharmacol Res Perspect. 2015;3:e0198.

23. (Imidazol-1-yl-methyl)-pyridazine as nmda receptor blocker. Buettelmann B, Heitz NMP, Jaeschke G, Pinard E, inventors. F. Hoffmann-La Roche Ad, assignee. International patent application PCT/EP2003/005151. May 16, 2003.

24. Chenard BL, Bordner J, Butler TW, et al. (1S,2S)-1-(4-hydroxyphenyl)-2-(4hydroxy-4-phenylpiperidino)-1-propanol: a potent new neuroprotectant which blocks N-methyl-D-aspartate responses. J Med Chem. 1995;38:3138-3145.

25. Steece-Collier K, Chambers LK, Jaw-Tsai SS, Menniti FS, Greenamyre JT. Antiparkinsonian actions of CP-101,606, an antagonist of NR2B subunit-containing N-methyl-d-aspartate receptors. Exp Neurol. 2000;163:239-243. 